\title{
The global prevalence of familial multiple sclerosis: an updated systematic review and meta-analysis
}

\author{
Naeim Ehtesham ${ }^{1,2^{*}}$ D, Maryam Zare Rafie ${ }^{3}$ and Meysam Mosallaei ${ }^{2}$
}

\begin{abstract}
Background: Considering that many recent studies have reported the prevalence of familial multiple sclerosis (FMS), we performed an updated meta-analysis of the worldwide prevalence of FMS by the addition of recent publications.
\end{abstract}

Methods: A search in PubMed, Scopus, the ISI Web of Science, and Google Scholar was undertaken up to 20 December 2020. The inclusion criteria were based on the CoCoPop approach (condition, context, and population). Meta-analysis of the qualified studies was conducted by comprehensive meta-analysis ver. 2 software.

Results: The pooled prevalence of MS in relatives of 16,179 FMS cases was estimated to be $11.8 \%$ (95\% Cl: 10.7-13) based on a random-effects model. The pooled mean age of disease onset in adult probands was calculated to be 28.7 years (95\% Cl: $27.2 \pm 30.2$ ). Regarding 13 studies that reported the data of FMS in pediatrics $(n=877)$ and adults $(n=6636)$, the FMS prevalence in pediatrics and adults was 15.5\% (95\% Cl: 13.8-17.4) and $10.8 \%(95 \% \mathrm{Cl}: 8.1-14.2)$, respectively. The prevalence of FMS in affected males $(n=5243)$ and females $(n=11,503)$ was calculated to be $13.7 \%$ (95\% Cl: $10.1-18.2)$ and $15.4 \%(95 \% \mathrm{Cl}: 10.3-22.4)$, respectively. The odds ratio of male/female in FMS cases was not statistically significant $(\mathrm{OR}=0.9 ; 95 \% \mathrm{Cl}$ : 0.6-1.2, $P=0.55)$. Subgroup analysis demonstrated a significant difference in the prevalence of FMS between the geographical areas $(P=0.007)$. The meta-regression model indicated that the prevalence of FMS is lower with higher latitude and higher MS prevalence $(P<0.001)$. In contrast, meta-regression based on prevalence day was not statistically significant $(P=0.29)$.

Conclusions: The prevalence of FMS is higher in the pediatric group than that of adults, distinct between geographical areas, and diminishes with the increment of MS prevalence and latitude. Also, the symptoms initiate relatively at younger ages in the FMS cases. Interestingly, our analysis unveiled that FMS is not more prevalent in men than women and the risk of MS development in relatives is not higher when the affected proband is male.

Keywords: Familial multiple sclerosis, Pediatric-onset multiple sclerosis, Systematic review, Meta-analysis

\footnotetext{
* Correspondence: na.ehtesham@uswr.ac.ir; Naeim.ehtesham@yahoo.com

${ }^{1}$ Student Research Committee, University of Social Welfare and Rehabilitation Sciences, Koodakyar Alley, Daneshjoo Blvd., Evin St, Tehran, Iran

${ }^{2}$ Department of Genetics and Molecular Biology, School of Medicine, Isfahan University of Medical Sciences, Isfahan, Iran

Full list of author information is available at the end of the article
} 


\section{Background}

Multiple sclerosis (MS), chronic inflammatory demyelinating disorder of the central nervous system, is the most common cause of non-traumatic neurological disability in a range of age groups especially young adults and afflicts more than 2.5 million individuals in the world [1]. Both genetic variations and environmental factors partake synergistically in the development of MS. The effect size of genetic risk factors ranges from small to modest. For instance, HLA-DRB1*15:01, as the major genetic determinant, has an odds ratio $(\mathrm{OR}) \sim 3.5$, which increases to 8 in homozygous carriers [2,3] The identified environmental risk triggers for MS development subsumes distance from the equator (latitude), vitamin D deficiency, lack of sunlight, smoking, obesity, and most importantly infection by Epstein-Barr virus, which is the largest environmental risk (OR 3.6) [4]. The heterogeneous distribution of $\mathrm{MS}$ in distinct populations has been attributed to the interplay between different genetic backgrounds and environmental exposures [5].

The earliest report of the existence of MS in more than one family member (familial MS or FMS) dates back to 1938 [6]. In the years since then, many studies have revealed the prevalence of FMS in many populations. All of them considered FMS as the occurrence of the same disease in at least one any-degree relative of patients. However, two nationwide register-based studies in Denmark did not consider the presence of MS in distant relatives comprising 2nd or 3rd-degree relatives as FMS cases [7, 8].

In this study, we aimed to perform an updated systematic review and meta-analysis about the worldwide prevalence of FMS by the addition of new studies. In contrast to the previous study [9], we conducted a separate meta-analysis on the prevalence of FMS in pediatriconset MS (POMS) and adult-onset MS (AOMS) as well as men and women. Also, subgroup analysis based on geographical area, and meta-regression based on latitude, prevalence date, and MS prevalence was conducted. In addition, we accomplished a meta-analysis of sex ratio and mean age of onset among FMS cases.

\section{Methods}

Preferred Reporting Items for Systematic Reviews and Meta-Analyses (PRISMA) guidelines [10] were recruited to perform the present systematic review focusing on the prevalence of FMS in the world. Each process of research was done independently by two investigators and disagreements were resolved by discussion with the third author.

\section{Search strategy}

We accomplished a comprehensive search in PubMed, Scopus, and the ISI Web of Science up to 20 December 2020. Boolean operators (AND \& OR) were utilized to search by a combination of these keywords: "multiple sclerosis", "familial", "epidemiology", "prevalence”, "incidence", "recurrence" and "frequency". The details of the search strategy are documented in Additional file 1. Finally, Google Scholar was searched to find further works. No language or date restriction was applied to the literature search. We manually checked the reference lists of obtained articles to not miss any additional documents.

\section{Eligibility criteria}

For defining the criteria for inclusion and exclusion of studies, we employed the CoCoPop approach (condition, context, and population) which is used for systematic reviews of prevalence studies [11]. According to this approach, the original studies with available full-text that have investigated the prevalence of MS in full biological relatives of patients with definite MS (not probable, possible, or suspected), and have been conducted in a specific region, time, and target population were enrolled. The reason behind the criteria for definite MS is that some neurological disorders mimic MS. The studies in the same region but with different time periods and sample frames were also included. Studies with duplicate data were excluded.

\section{Data extraction}

By using a pre-prepared sheet, these data were collected from the eligible studies: first author's last name, publication year, prevalence day or period (the time point or period that the FMS prevalence was determined), setting and case ascertainment, the place of the research, diagnostic criteria of probands, the method for the ascertainment of MS in relatives, the number of FMS cases and total patients, mean age of disease onset in probands, the prevalence of MS, the number of POMS in FMS cases, geographical area, and sex ratio of probands. For providing insight into the difference between the prevalence of FMS in adults and pediatrics, the studies that reported FMS prevalence in AOMS and POMS separately were considered as two different data sets.

\section{Quality assessment}

For assessing the methodological quality of included studies, Joanna Briggs Institute's critical appraisal tool was exploited which comprises 9 questions [12]. If the answer to a question was "Yes", 1 score was considered. Points 0$5,6-7$, and 8-9 were regarded as low, moderate, and high quality, respectively. The minimum score for enrolment of the studies was 5 . This was because, in some of the studies with a 5 score, one or more quality parameters were ambiguous. In other words, these studies had borderline quality and could be regarded as studies with moderate quality.

\section{Statistical analysis}

For choosing between random-effects and fixed-effects models, heterogeneity of studies was evaluated by 
Cochran's $\mathrm{Q}$ and $\mathrm{I}^{2}$ tests. For verification of the stability of data, a sensitivity analysis was performed. In addition to a meta-analysis of the prevalence of FMS in all studies, a separate analysis was implemented on studies that reported, separately, the prevalence of FMS in AOMS and POMS cases and males and females. By using the number of FMS and total MS in male and female groups, we calculated the odds ratio (OR) and 95\% CI of prevalence to estimate the effect of gender. To find the underlying cause of heterogeneity, subgroup analysis was performed based on geographical area and meta-regression was carried out in terms of latitude, MS prevalence, and prevalence day. We assessed the publication bias by using Begg and Egger's tests. Comprehensive meta-analysis ver. 2 software was utilized for analysis and statistical significance was set at a $p$-value $<0.05$.

\section{Results}

\section{Literature search and characteristics}

Collectively, database and manual search led to the finding of 739 and 7 records, respectively. Obtaining only 7 additional works by manual search indicates that our search strategy was robust and did not affect the integrity of our review. After removal of duplicates, initial screening was performed based on titles and abstracts which left 119 articles for assessment of the full-text. Of these, 73 articles were excluded for these reasons (Additional file 2): six had duplicate data, three considered more than one specific region, six did not determine the prevalence day, five reported the data in a combination of Neuromyelitis Optica (NMO), acquired demyelinating syndromes (ADS) and MS cases, two were performed in two or more populations and time periods, one without available of the full-text, 25 with the inclusion of probable and/or possible cases, 24 low-quality studies and one with no determination of the target population. Finally, 49 studies from 46 articles with a sample size of 16,179 FMS cases were included in our analysis (Fig. 1). The characteristics of these studies are represented in Table 1. The eligible articles have been published from 1984 to 2020 and regardless of six studies, the rest of included studies had a crosssectional design.

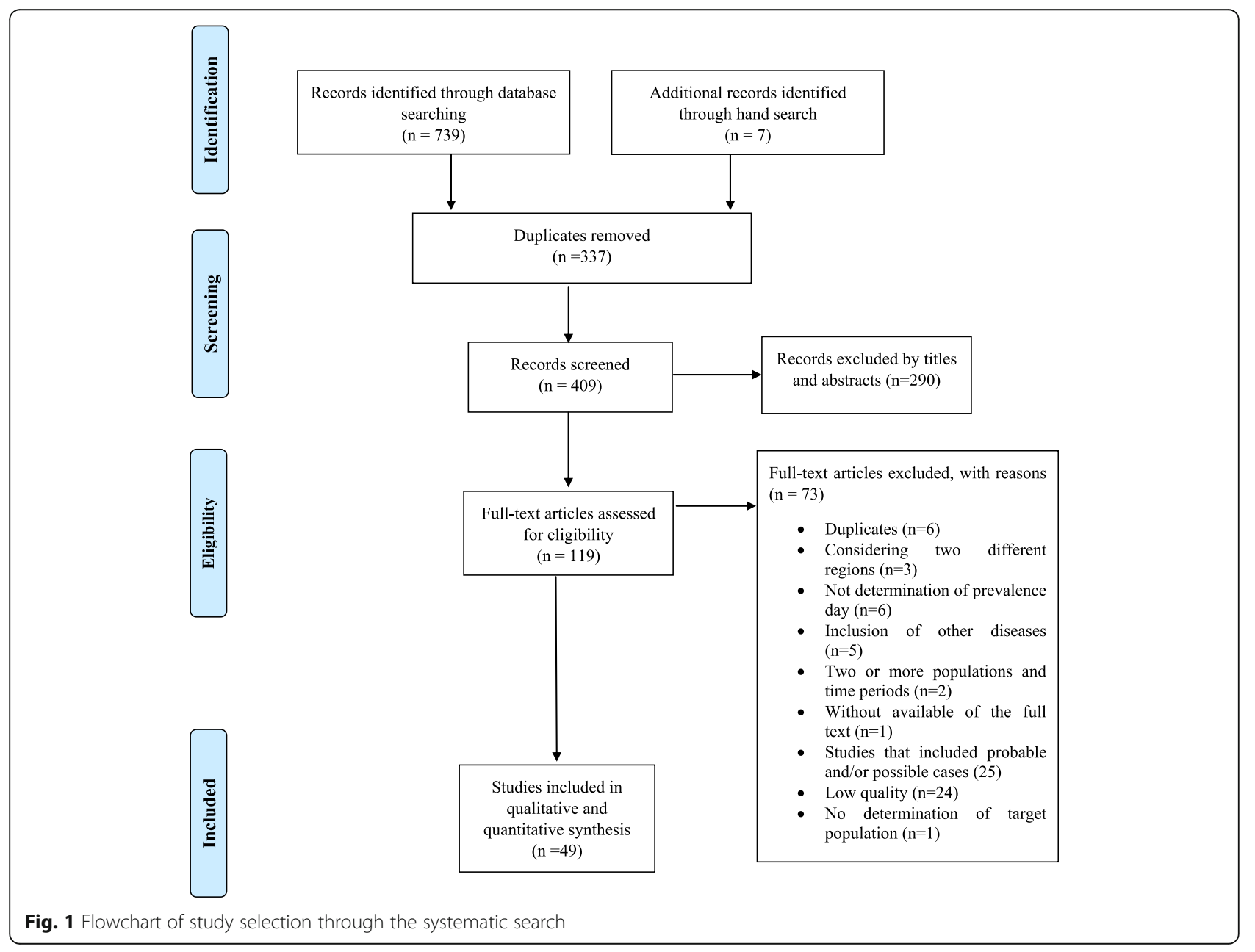




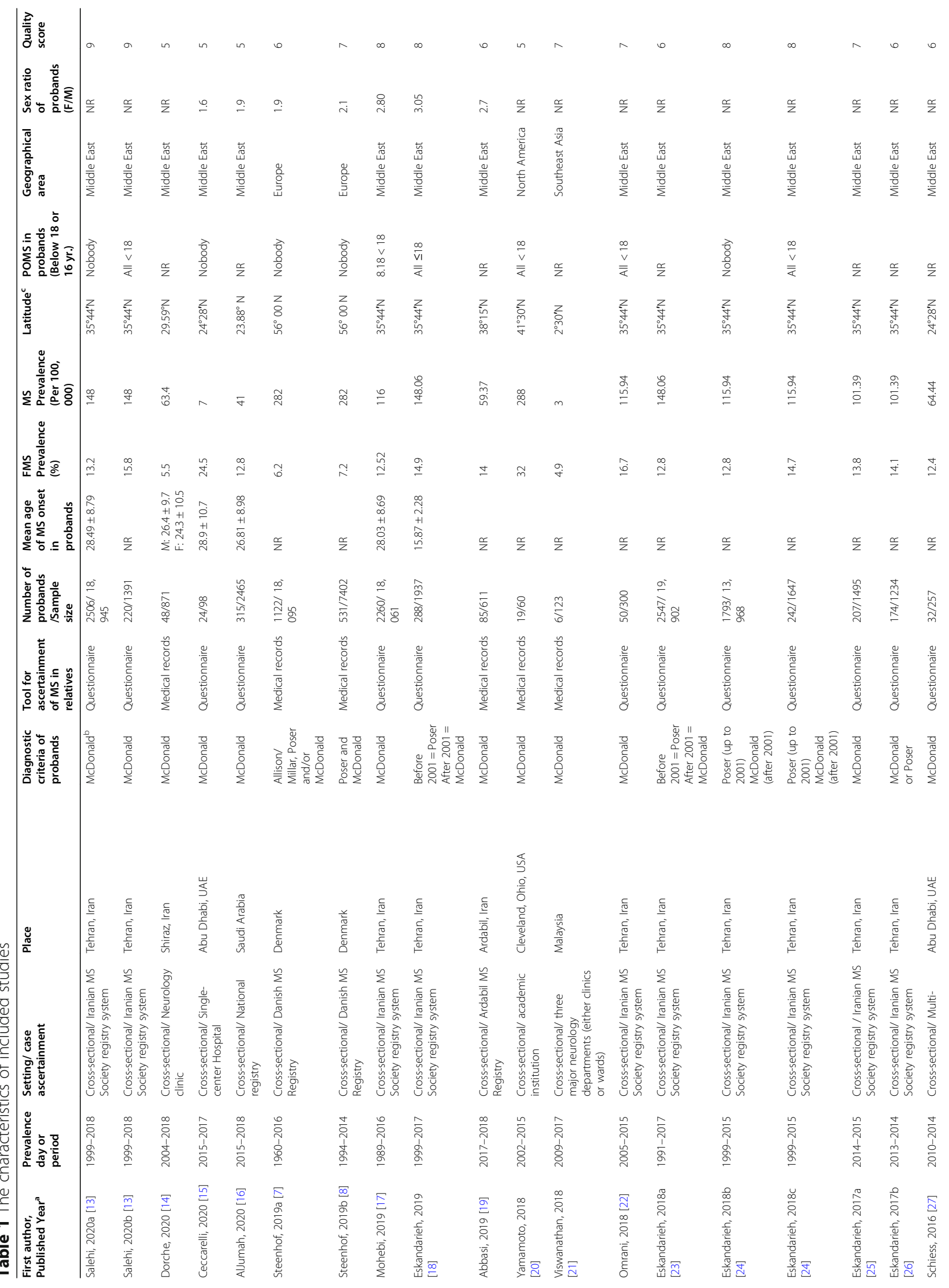




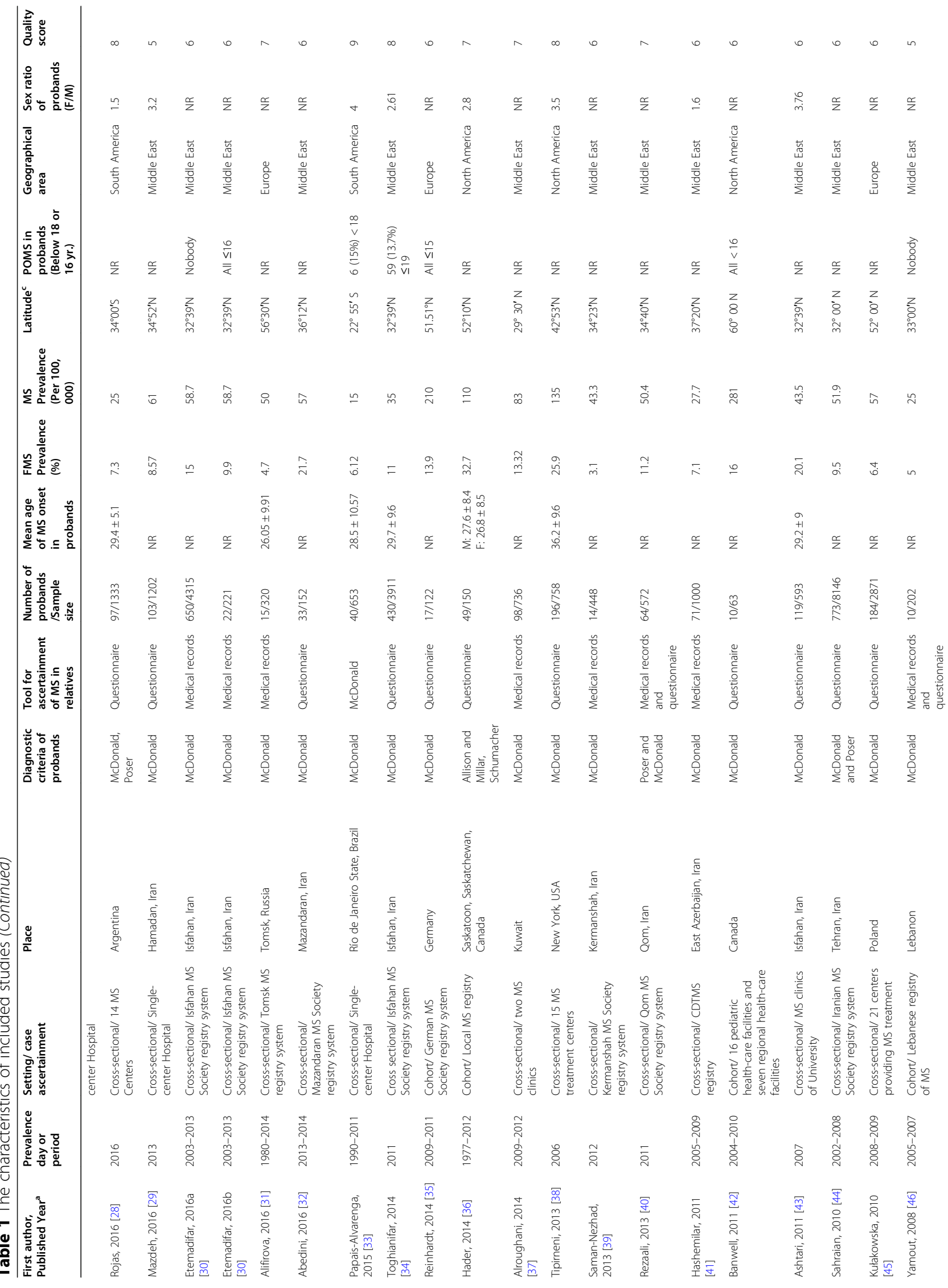




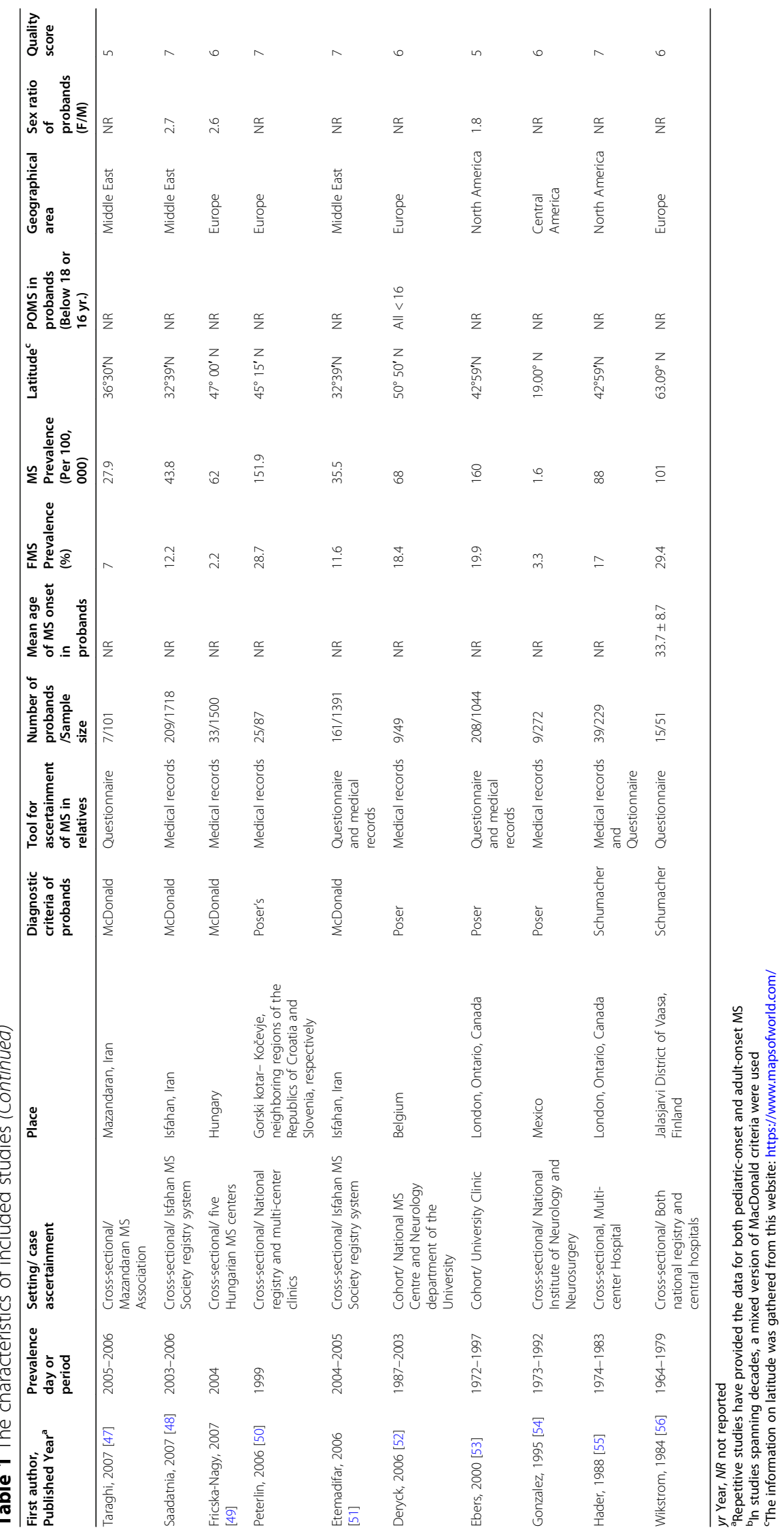




\section{Meta-analysis of whole data}

Because of high total heterogeneity $\left(\mathrm{Q}=1662.2, \mathrm{I}^{2}=\right.$ $97.112 \%$ and $P<0.001)$, a random-effects model was used. The polled prevalence of FMS was estimated to be $11.8 \%$ (95\% CI: 10.7-13) of the total MS population (Fig. 2). The highest and lowest prevalence was found in Saskatchewan of Canada (32.7\%) [36] and Hungary (2.2\%) [49], respectively. The sensitivity analysis indicated our robust pooled estimate (Fig. 3).

\section{Meta-analysis of mean age of onset in AOMS and prevalence of FMS in AOMS and POMS}

The pooled mean age of disease onset in AOMS probands of 15 studies $(n=6114)$ that reported this variable was 28.7 years (95\% CI: $27.2 \pm 30.2)$ (Fig. 4). In this regard, the lowest and highest age of disease onset was recorded in Shiraz city of Iran (24.3 years) and New York of USA (36.2 years), respectively. In 13 studies that reported the data of AOMS $(n=6636)$ and POMS $(n=$ 877), the FMS prevalence in AOMS was 10.8\% (95\% CI: 8.1-14.2) and in POMS was $15.5 \%$ (95\% CI: 13.8-17.4), respectively (Fig. 5). The difference between these two groups was statistically significant $(P=0.019)$.

Meta-analysis of FMS prevalence in men and women and OR of male/female

Nine studies provided the data of FMS and sporadic cases for men and women separately. Therefore, it was possible to calculate FMS prevalence for each sex separately. With regard to data of the 9 studies, the prevalence of FMS in affected males $(n=5243)$ and females

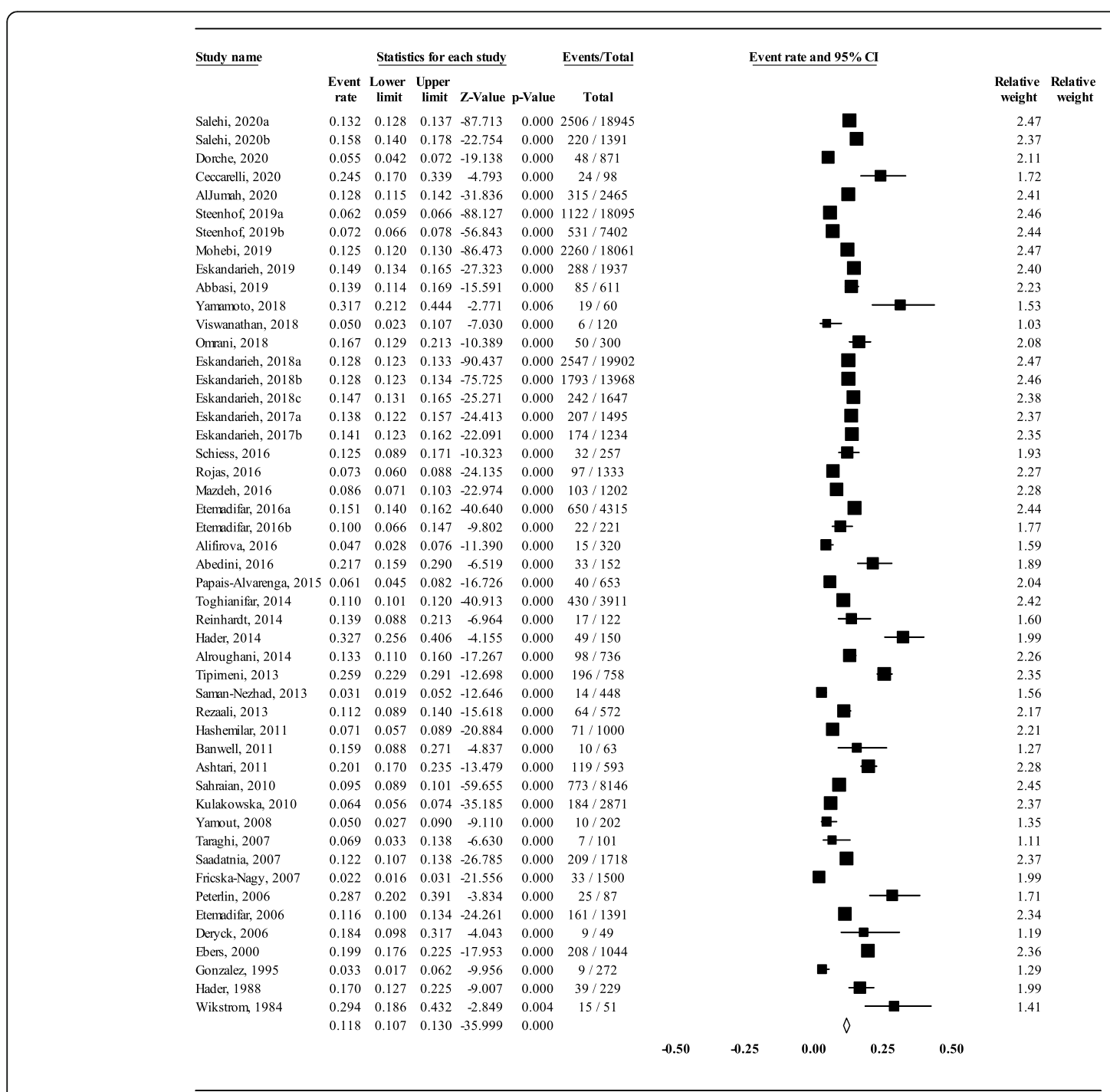

Fig. 2 The prevalence of FMS (Heterogeneity: $I^{2}=97.112 \%, P<0.001$, Random effects) 


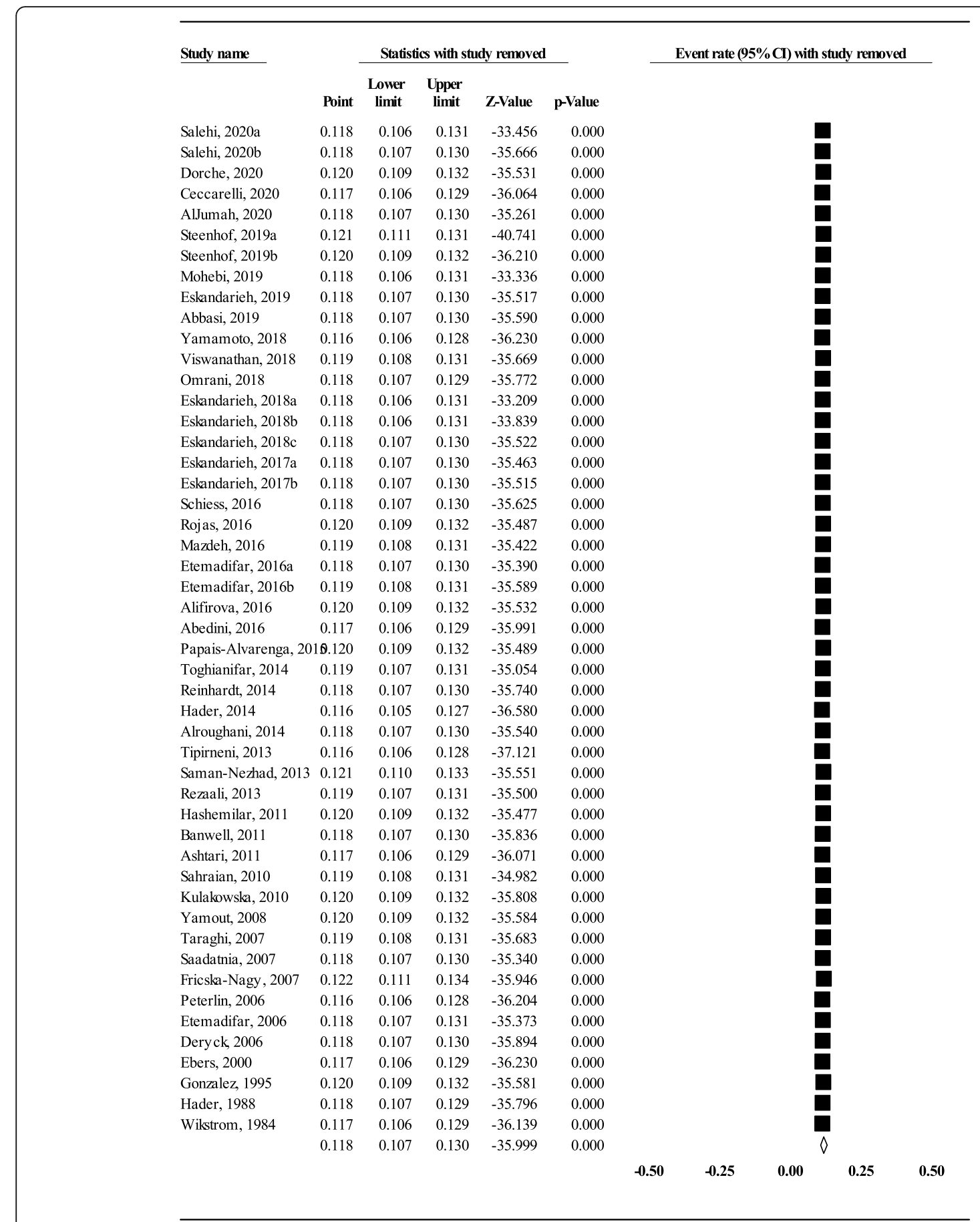

Fig. 3 Forest plot of sensitivity analysis

$(n=11,503)$ was calculated to be $13.7 \%$ (95\% CI: $10.1-$ 18.2) and $15.4 \%$ (95\% CI: 10.3-22.4), respectively (Fig. 6). In Fig. 6, in each study, the first number is the number of FMS cases and the second number is the number of FMS plus sporadic cases (both in that particular gender). For instance, in the study of AlJumah et al., 107 men and 208 women with FMS and 710 men and 1440 women with sporadic MS were recruited [16]; therefore, the rate of FMS in men and women was calculated to be $107 / 817(710+107)$ and 208/1648 $(208+1440)$, respectively. The OR of male/female in FMS cases was not statistically significant $(\mathrm{OR}=0.9 ; 95 \% \mathrm{CI}: 0.6-1.2, P=0.55)$ 


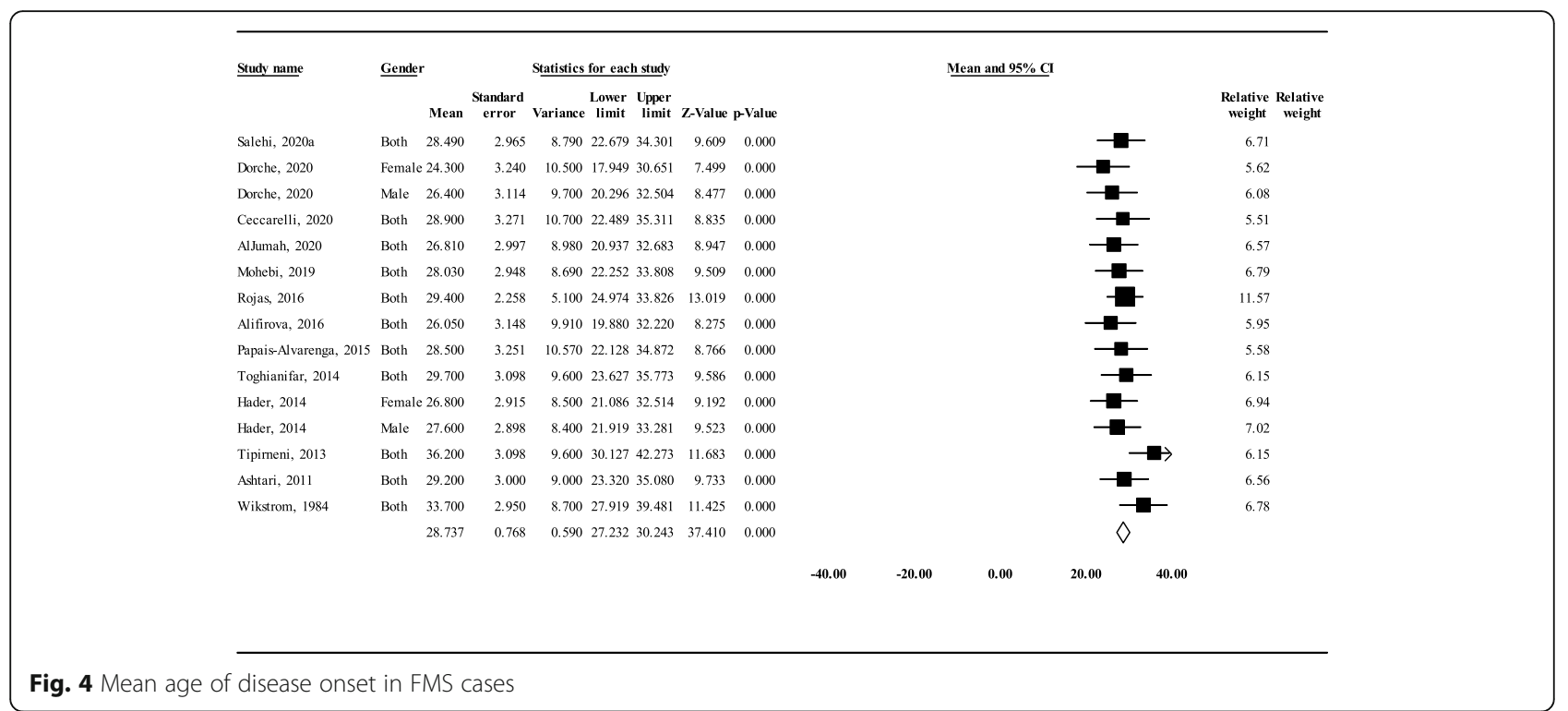

(Fig. 7). In Additional file 3, detailed data of each 9 studies and how the odds ratio was calculated is presented.

\section{Subgroup analysis and meta-regression}

Subgroup analysis revealed a significant difference in the prevalence of FMS between the geographical areas (Test for subgroup differences: $Q=12.070, \operatorname{df}(\mathrm{Q})=3, \quad P=$ 0.007) (Fig. 8).

The meta-regression model showed that FMS prevalence was significantly lower in higher latitude (meta-regression coefficient: $-0.025,95 \% \mathrm{CI}:-0.027$ to -0.023 , $P<0.001$ ) (Fig. 9A). Similarly, a slight downward trend was observed with higher MS prevalence (meta-regression coefficient: $-0.0018,95 \% \mathrm{CI}:-0.0021$ to -0.0016 , $P<0.001)$ (Fig. 9B). While, meta-regression based on prevalence day was not statistically significant (meta-regression coefficient: -0.002 , 95\% CI: -0.005 to 0.001 , $P=0.29$ ) (Fig. 9C).

\section{Publication bias}

No publication bias was found in our analysis (Egger = 0.98, and Begg's $=0.25$ ) as depicted in the funnel plot (Fig. 10).

\section{Discussion}

The results of a previous meta-analysis indicated that MS can run in families [57]. The pooled prevalence of FMS in our study (11.8\%) (Fig. 2) was lower than the previous meta-analysis (12.6\%) [9]. Hence, we performed a meta-regression analysis based on prevalence day to

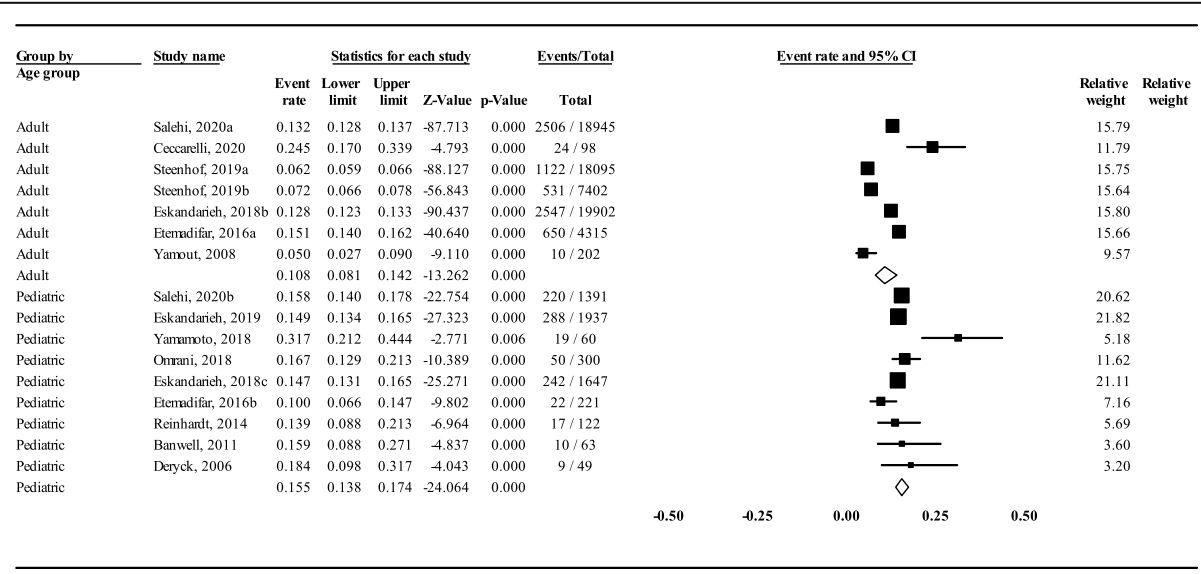

Fig. 5 The prevalence of FMS in POMS and AOMS cases 
$\underline{\mathbf{A}}$

\begin{tabular}{|c|c|c|c|c|c|c|}
\hline \multirow[t]{2}{*}{ Study name } & \multirow[b]{2}{*}{$\begin{array}{l}\text { Event } \\
\text { rate }\end{array}$} & \multicolumn{3}{|c|}{ Statistics for each study } & \multirow[b]{2}{*}{ p-Value } & \multirow[b]{2}{*}{ Total } \\
\hline & & $\begin{array}{c}\text { Lower } \\
\text { limit }\end{array}$ & $\begin{array}{l}\text { Upper } \\
\text { limit }\end{array}$ & Z-Value & & \\
\hline AlJumah, 2020 & 0.131 & 0.110 & 0.156 & -18.249 & 0.000 & $107 / 817$ \\
\hline Steenhof, 2019b & 0.072 & 0.062 & 0.083 & -32.158 & 0.000 & $170 / 2369$ \\
\hline Eskandarieh, 2019 & 0.169 & 0.136 & 0.207 & -12.256 & 0.000 & $71 / 421$ \\
\hline Rojas, 2016 & 0.085 & 0.062 & 0.115 & -14.011 & 0.000 & $38 / 447$ \\
\hline Hader, 2014 & 0.165 & 0.098 & 0.263 & -5.354 & 0.000 & $13 / 79$ \\
\hline Hashemilar, 2011 & 0.102 & 0.071 & 0.144 & -10.740 & 0.000 & $27 / 266$ \\
\hline Ashtari, 2011 & 0.240 & 0.168 & 0.332 & -5.014 & 0.000 & $25 / 104$ \\
\hline Saadatnia, 2007 & 0.147 & 0.115 & 0.186 & -12.154 & 0.000 & $56 / 381$ \\
\hline Ebers, 2000 & 0.206 & 0.167 & 0.251 & -10.335 & 0.000 & $74 / 359$ \\
\hline & 0.137 & 0.101 & 0.182 & -10.606 & 0.000 & \\
\hline
\end{tabular}

Event rate and $95 \% \mathrm{CI}$

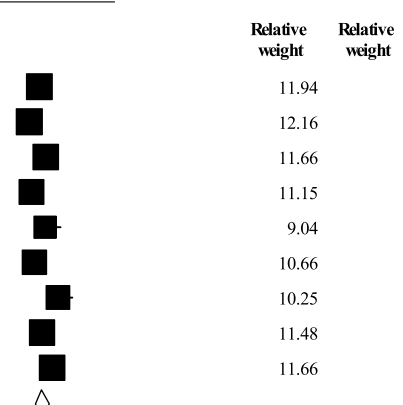

$\begin{array}{lllll}-1.00 & -0.50 & 0.00 & 0.50 & 1.00\end{array}$

\section{B}

\begin{tabular}{lccccccc} 
Study name & & \multicolumn{9}{c}{ Statistics for each study } & & \\
\cline { 4 - 6 } & & $\begin{array}{c}\text { Event } \\
\text { rate }\end{array}$ & $\begin{array}{c}\text { Lower } \\
\text { limit }\end{array}$ & $\begin{array}{c}\text { Upper } \\
\text { limit }\end{array}$ & Z-Value & p-Value & Total \\
AlJumah, 2020 & 0.126 & 0.111 & 0.143 & -26.085 & 0.000 & $208 / 1648$ \\
Steenhof, 2019b & 0.072 & 0.065 & 0.079 & -46.872 & 0.000 & $361 / 5033$ \\
Eskandarieh, 2019 & 0.146 & 0.129 & 0.164 & -24.090 & 0.000 & $217 / 1490$ \\
Rojas, 2016 & 0.067 & 0.052 & 0.085 & -19.593 & 0.000 & $59 / 886$ \\
Hader, 2014 & 0.507 & 0.392 & 0.621 & 0.119 & 0.906 & $36 / 71$ \\
Hashemilar, 2011 & 0.061 & 0.046 & 0.081 & -17.590 & 0.000 & $44 / 723$ \\
Ashtani, 2011 & 0.192 & 0.160 & 0.230 & -12.509 & 0.000 & $94 / 489$ \\
Saadatnia, 2007 & 0.320 & 0.280 & 0.363 & -7.684 & 0.000 & $153 / 478$ \\
Ebers, 2000 & 0.196 & 0.168 & 0.227 & -14.679 & 0.000 & $134 / 685$ \\
& 0.154 & 0.103 & 0.224 & -7.209 & 0.000 &
\end{tabular}

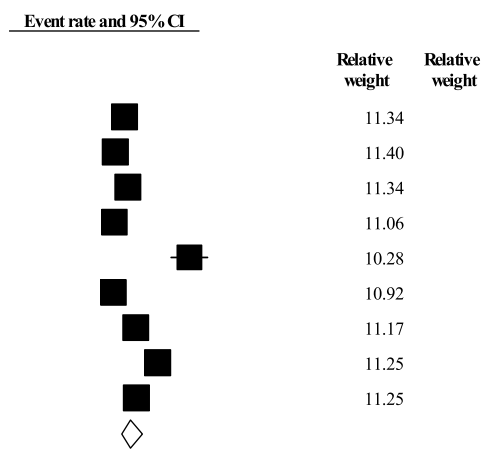

$\begin{array}{rrrrr}-1.00 & -0.50 & 0.00 & 0.50 & 1.00\end{array}$

Fig. 6 The prevalence of FMS in men (A) and women (B)

examine if the prevalence of the FMS has been decreased over time. Our results showed a non-significant lowering trend (Fig. 9C). Hence, it seems that the worldwide frequency of FMS is steady-state over time. Nonetheless, some studies in middle-east have reported the increasing [13, 24] or decreasing [16] prevalence of FMS over time. The overwhelming majority of the studies have been performed in a cross-sectional setting; while, a sufficiently long follow-up period is needed to evaluate the development of the disease in new members of the relatives. In this regard, cohort studies could be well suited on the account of a longer time period for the accumulation of new cases in the family.

POMS is defined as the manifestation of MS symptoms under the age of 16 or 18 [58]. According to our analysis, the frequency of FMS in POMS was higher than AOMS (Fig. 5). However, only 3 to $10 \%$ of sporadic cases have been reported to be POMS [59]. This informs us that increased genetic load may be a pivotal feature of POMS and the family history of MS could be a crucial contributing factor for POMS predisposition. Considering that association between HLA-DRB1*15:01 and age at onset shows a 10.6 


\begin{tabular}{|c|c|c|c|c|c|c|c|}
\hline \multirow[t]{2}{*}{ Study name } & \multirow[b]{2}{*}{$\begin{array}{l}\text { Odds } \\
\text { ratio }\end{array}$} & \multicolumn{3}{|c|}{ Statistics for each study } & \multicolumn{3}{|c|}{ FMS / Total } \\
\hline & & $\begin{array}{l}\text { Lower } \\
\text { limit }\end{array}$ & $\begin{array}{l}\text { Upper } \\
\text { limit }\end{array}$ & ZValue & p-Value & Male & Female \\
\hline AlJumah, 2020 & 1.043 & 0.813 & 1.340 & 0.333 & 0.739 & $107 / 817$ & $208 / 1648$ \\
\hline Steenhof, 2019b & 1.001 & 0.828 & 1.209 & 0.005 & 0.996 & $170 / 2369$ & $361 / 5033$ \\
\hline Eskandarieh, 2019 & 1.190 & 0.888 & 1.595 & 1.164 & 0.244 & $71 / 421$ & $217 / 1490$ \\
\hline Rojas, 2016 & 1.302 & 0.852 & 1.991 & 1.219 & 0.223 & $38 / 447$ & $59 / 886$ \\
\hline Hader, 2014 & 0.191 & 0.090 & 0.407 & -4.290 & 0.000 & $13 / 79$ & $36 / 71$ \\
\hline Hashemilar, 2011 & 1.743 & 1.056 & 2.878 & 2.173 & 0.030 & $27 / 266$ & $44 / 723$ \\
\hline Ashtari, 2011 & 1.330 & 0.804 & 2.199 & 1.111 & 0.267 & $25 / 104$ & $94 / 489$ \\
\hline Saadatnia, 2007 & 0.366 & 0.260 & 0.516 & -5.751 & 0.000 & $56 / 381$ & $153 / 478$ \\
\hline \multirow[t]{2}{*}{ Ebers, 2000} & 1.068 & 0.777 & 1.467 & 0.404 & 0.686 & $74 / 359$ & $134 / 685$ \\
\hline & 0.909 & 0.666 & 1.241 & -0.598 & 0.550 & & \\
\hline
\end{tabular}

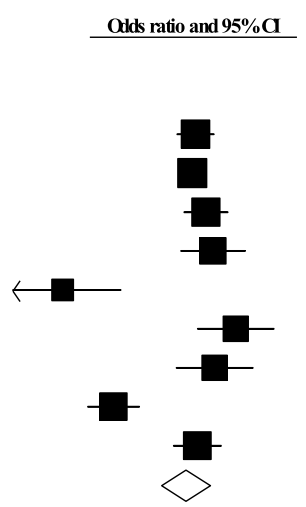

0.1

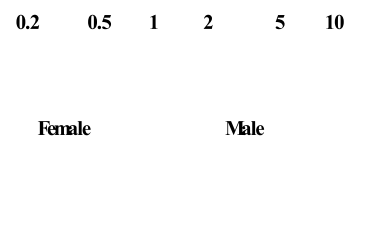

Fig. 7 The OR of male/female among FMS cases

months reduction in age at onset with each DRB1*15:01 allele [60], the difference between POMS and AOMS could be attributed to the higher frequency of DRB1*15:01 in POMS compared with AOMS [61]. By considering followup time bias, it seems that the prevalence of FMS is underestimated in the pediatric group due to not emergence of this disease in relatives especially siblings at the time of the study, at least in cross-sectional studies.

The mean age of onset in adult probands with FMS was estimated to be 28.7 (Fig. 4), which indicates an earlier age of onset among FMS cases in comparison to sporadic cases $[7,62]$. This highlights the point that the preclinical phase of the disease would be shortened in cases with higher genetic load and consequently, symptoms initiate at a lower age at onset. In this regard, as previously mentioned, several studies have indicated that HLA, especially HLA-DRB1*15:01, is the main genetic influence on age of disease onset [63-65].

Given the concept of the "carter effect" [66], we set out to investigate the notion that in male MS patients, the prevalence of FMS is more than in females patients, as well as transmission to other members of the family, is higher when the affected individual is male. However, the prevalence of FMS in male and female cases and OR of male/female FMS cases did not confirm this theory (Figs. 6 and 7). This represents that a greater than average background of susceptibility factors in an affected male which is the less frequently affected sex does not increase the occurrence of the MS in relatives. On the contrary, a higher prevalence of FMS and positive family in males than that in females was seen in the Iranian population [67]. Regarding this discrepancy, we acknowledge that the low sample size for scrutinizing the effect of sex may lead to this interpretation.

Subgroup analysis unveiled that the distribution of FMS is different between geographical areas (Fig. 8). However, even between different studies in the same geographical area, the FMS prevalence is different, mirroring that this difference is more complicated than can be explained only by just differences in susceptibility between racial and ethnic groups. Also, this finding could justify the high heterogeneity between studies, at least in part. Relevantly, other meta-analysis indicated different FMS prevalence in Iran (8.9\%) [67] and the Middle East North Africa region (17.8\%) [68].

It is expected that with the increasing prevalence of sporadic MS, the frequency of FMS rises, as well. Quite interestingly, our meta-regression analysis revealed a weak decreasing trend of FMS with higher MS prevalence (Fig. 9A). In the same vein, meta-regression in terms of latitude disclosed that the prevalence of FMS is decreased in conjunction with an increment of latitude (Fig. 9B); although, traditionally, MS has been more prevalent in regions at higher latitudes with decreased sunlight exposure [69]. Intriguingly, without conducting a statistical analysis, Harirchian and coworkers concluded that the prevalence of FMS was not latitude dependent. We addressed this issue in our study and found that at odds with the previous study the prevalence of FMS is latitude dependent. Thereby, we 


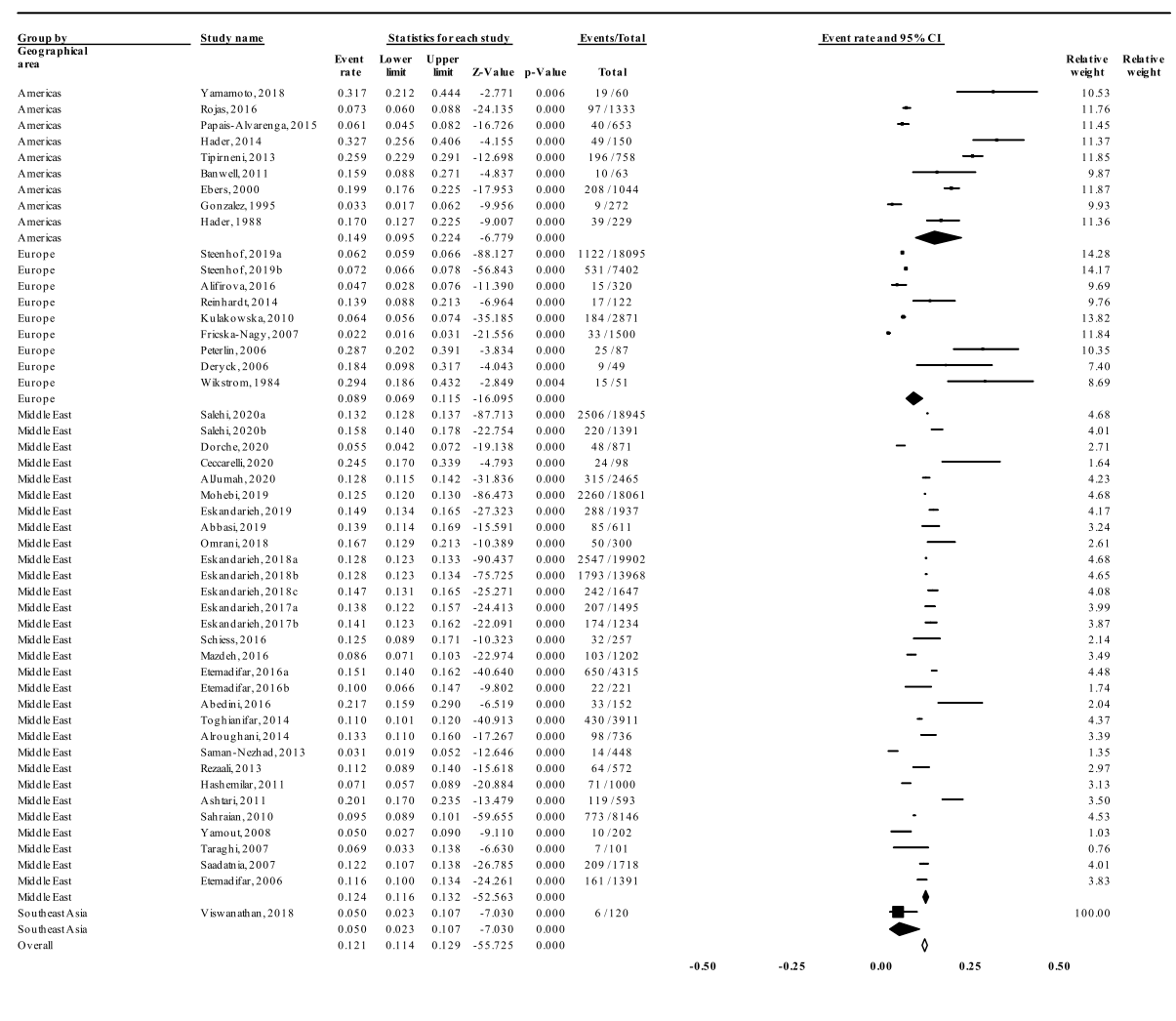

Fig. 8 The prevalence of FMS in different geographical areas

hypothesized that with the increasing frequency of MS in a region, the public awareness and familiarity of the people, especially genetic counselors, with the disease grows, too. Therefore, the rate of marriages in which one or both sides have one or more affected members reduces. This, in turn, lowers the shared genetic variants in families. On the other hand, the rate of consanguineous marriage as a predictor of positive family history of MS [16], will most probably be diminished in regions with a high outbreak of this disease.

In comparison to the previous systematic review [9], the strengths of our study were recruiting of a quality assessment tool for inclusion of studies, no limitation of language for searching of articles, uncovering the prevalence of FMS in different geographical areas, in POMS and AOMS cases, and men and women, unveiling the relationship between the prevalence of FMS and prevalence day, MS prevalence and latitude, determining the mean age of the disease onset in adult probands and the effect of gender on FMS occurrence. However, we acknowledge that it would have been better if other databases such as Embase had been examined. Notwithstanding, there are some issues in the included studies which mostly are derived from the retrospective design. For instance, recall bias could occur when the presence of affected relatives is assessed by employing questionnaires and medical records which hinges on patients' self-reporting. This might result in the under-diagnosis of distant relatives. On the other hand, the diversity in case ascertainment methodology namely population (registry or community)-based or clinical (hospital)-based may cause the sampling bias.

\section{Conclusion}

In summary, the findings of this study demonstrated that the prevalence of FMS is higher in POMS cases than that of AOMS, is different between geographical areas, and reduces with the higher MS prevalence and latitude. Likewise, the symptoms embark relatively at lower ages in FMS probands of AOMS. Unexpectedly, the prevalence of FMS was not more prevalent in men than women and the risk of MS development in relatives was not higher when the affected proband was male. For preventing biases, we suggest that future studies be performed as longitudinal prospective to provide time for the development of new cases in relatives. Also, the reported affected members of the family must be reexamined by neurologists. 


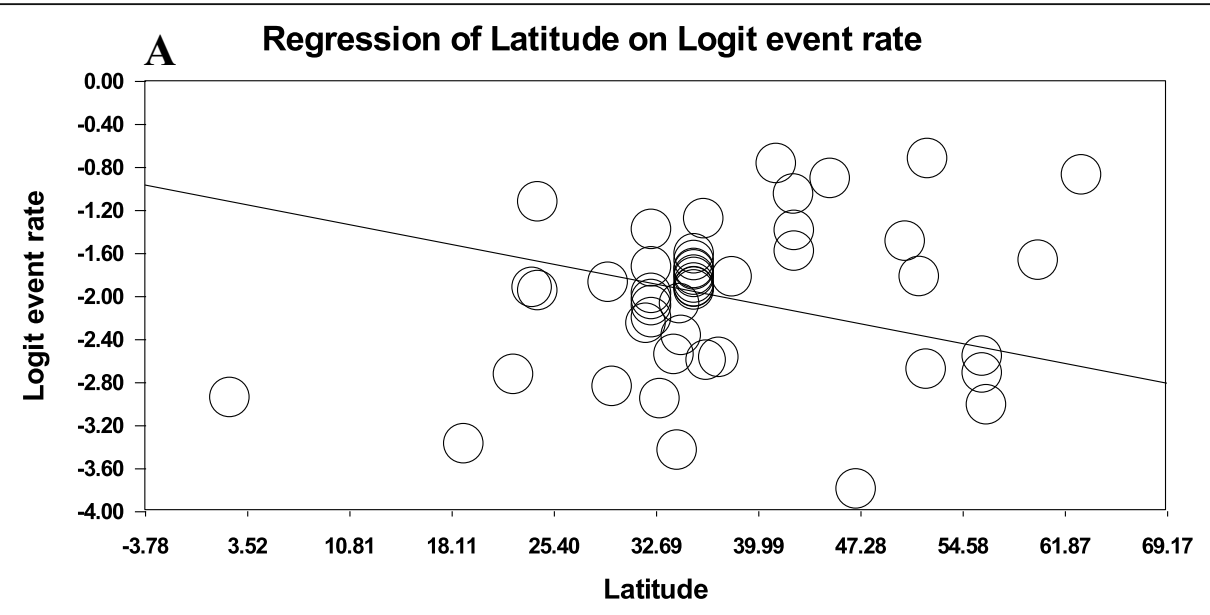

B Regression of MS Prevalence on Logit event rate

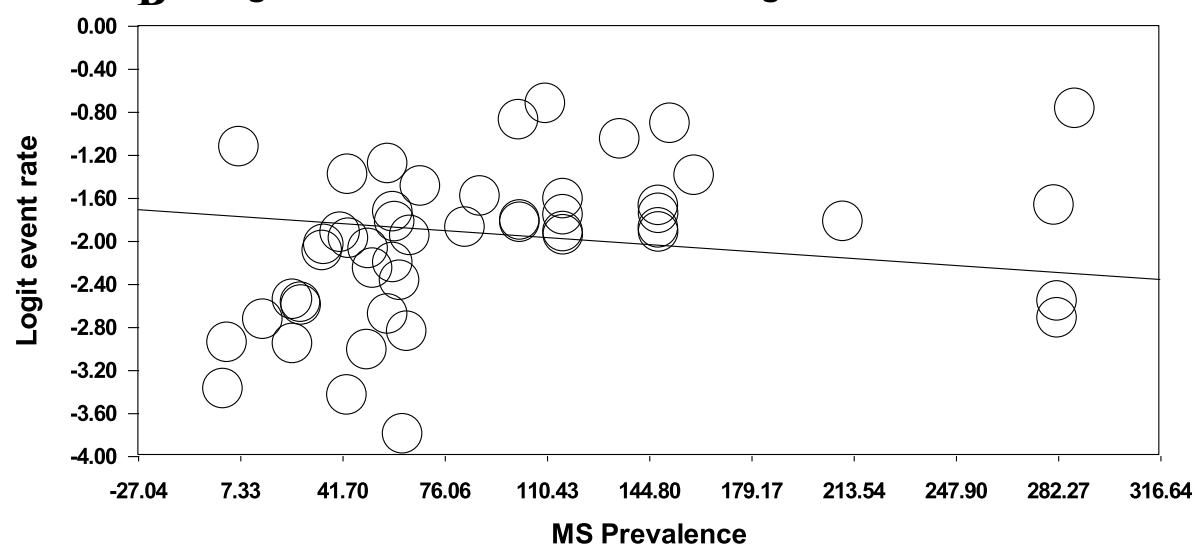

C Regression of Prevalance day on Logit event rate

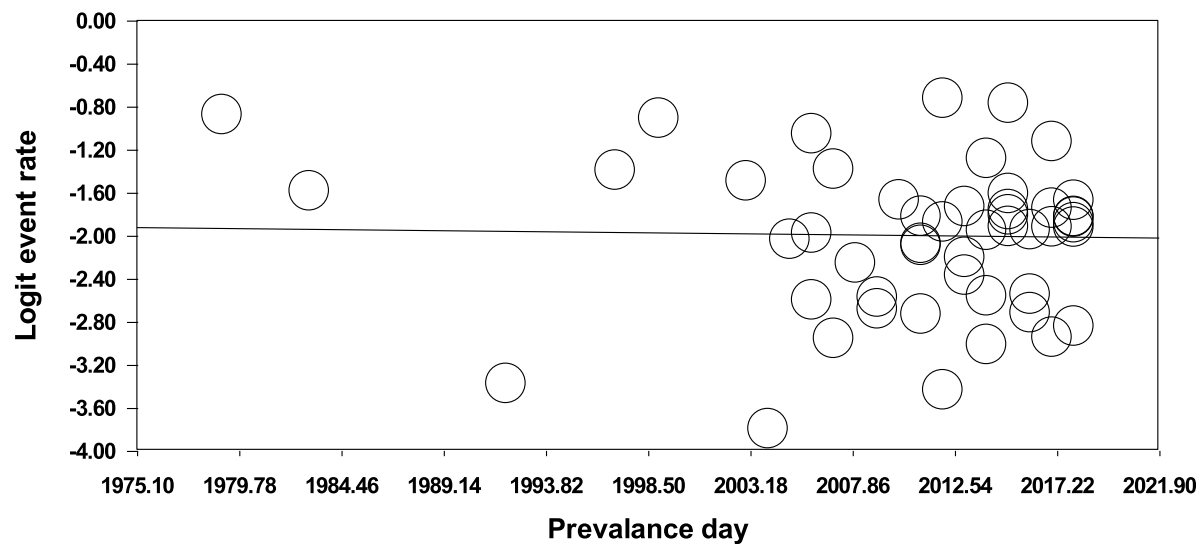

Fig. 9 Meta-regression analysis of FMS prevalence in terms of latitude (meta-regression coefficient: $-0.025,95 \% \mathrm{Cl}:-0.027$ to $-0.023, P<0.001)(\mathbf{A})$, MS prevalence (meta-regression coefficient: $-0.0018,95 \% \mathrm{Cl}:-0.0021$ to $-0.0016, P<0.001)(\mathbf{B})$, and prevalence day (meta-regression coefficient: $-0.002,95 \%$ Cl: -0.005 to $0.001, P=0.29)(\mathbf{C})$ 
Funnel Plot of Standard Error by Logit event rate

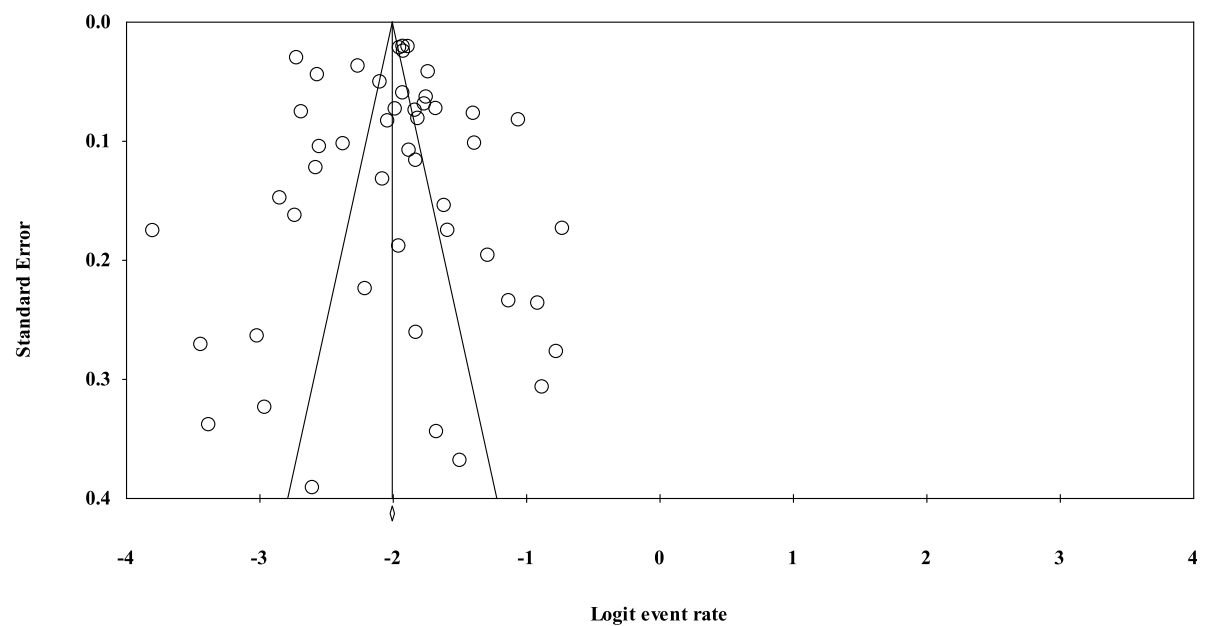

Fig. 10 Funnel plot of publication bias

\section{Abbreviations}

MS: Multiple sclerosis; FMS: Familial multiple sclerosis; POMS: Pediatric-onset MS; AOMS: Adult-onset MS; PRISMA: Preferred Reporting Items for Systematic Reviews and Meta-Analyses; CoCoPop: Condition, context, and population; OR: Odds ratio

\section{Supplementary Information}

The online version contains supplementary material available at https://doi. org/10.1186/s12883-021-02267-9.

Additional file 1. The search strategy that was used in the databases.

Additional file 2. Excluded studies with reason

Additional file 3. The data of 9 studies that provided the number of familial and sporadic cases for men and women to calculate the prevalence of FMS separately for each gender and also the odds ratio (Section 3.4)

\section{Acknowledgements}

Not applicable.

\section{Authors' contributions}

NE performed writing, supervision, conceptualization, and review. MZR accomplished data curation, formal analysis, and editing. MM conducted data curation and formal analysis. All authors have read and reviewed critically and approved the final manuscript.

\section{Funding}

Not applicable.

\section{Availability of data and materials}

All data generated or analysed during this study are included in this published article [and its supplementary information files].

\section{Declarations}

Ethics approval and consent to participate

Not applicable.

\section{Consent for publication}

Not applicable.

\section{Competing interests}

The authors declare that they have no competing interests.

\section{Author details}

${ }^{1}$ Student Research Committee, University of Social Welfare and Rehabilitation Sciences, Koodakyar Alley, Daneshjoo Blvd., Evin St, Tehran, Iran. ²Department of Genetics and Molecular Biology, School of Medicine, Isfahan University of Medical Sciences, Isfahan, Iran. ${ }^{3}$ School of Medicine, Zanjan University of Medical Sciences, Zanjan, Iran.

Received: 17 February 2021 Accepted: 3 June 2021

Published online: 28 June 2021

\section{References}

1. Ehtesham N, Mosallaei M, Karimzadeh MR, Moradikazerouni H, Sharifi M. microRNAs: key modulators of disease-modifying therapies in multiple sclerosis. Int Rev Immunol. 2020;39(6):264-79. https://doi.org/10.1080/0883 0185.2020.1779712.

2. Moutsianas $L$, Jostins $L$, Beecham AH, Dilthey AT, Xifara DK, Ban M, et al. Class II HLA interactions modulate genetic risk for multiple sclerosis. Nat Genet. 2015:47(10):1107-13. https://doi.org/10.1038/ng.3395.

3. Patsopoulos N, Baranzini S, Santaniello A, Shoostari P, Cotsapas C, Wong G, et al. Multiple sclerosis genomic map implicates peripheral immune cells and microglia in susceptibility. Science. 2019;365:1-10. https://doi.org/10.112 6/science.aav7188.

4. Nourbakhsh B, Mowry EM. Multiple sclerosis risk factors and pathogenesis. Continuum (Minneap Minn). 2019;25(3):596-610. https://doi.org/10.1212/ con.0000000000000725.

5. Koch-Henriksen N, Sørensen PS. The changing demographic pattern of multiple sclerosis epidemiology. Lancet Neurol. 2010;9(5):520-32. https://doi. org/10.1016/s1474-4422(10)70064-8

6. Curtius F, Speer H. Multiple Sklerose und Erbanlage. Zeitschrift für die gesamte Neurologie und Psychiatrie. 1938;160(1):226-45. https://doi.org/1 $0.1007 / B F 02877977$

7. Steenhof M, Stenager E, Nielsen NM, Kyvik K, Möller S, Hertz JM. Familial multiple sclerosis patients have a shorter delay in diagnosis than sporadic cases. Mult Scler Relat Disord. 2019;32:97-102. https://doi.org/10.1016/j.msa rd.2019.04.012.

8. Steenhof M, Nielsen NM, Stenager E, Kyvik K, Möller S, Hertz JM. Distribution of disease courses in familial vs sporadic multiple sclerosis. Acta Neurol Scand. 2019:139(3):231-7. https://doi.org/10.1111/ane.13044.

9. Harirchian $\mathrm{MH}$, Fatehi F, Sarraf P, Honarvar NM, Bitarafan S. Worldwide prevalence of familial multiple sclerosis: a systematic review and metaanalysis. Mult Scler Relat Disord. 2018;20:43-7. https://doi.org/10.1016/j.msa rd.2017.12.015.

10. Moher D, Liberati A, Tetzlaff J, Altman DG. Preferred reporting items for systematic reviews and meta-analyses: the PRISMA statement. PLoS Med. 2009;6(7):e1000097. https://doi.org/10.1371/journal.pmed.1000097. 
11. Hoffmann F, Eggers D, Pieper D, Zeeb H, Allers K. An observational study found large methodological heterogeneity in systematic reviews addressing prevalence and cumulative incidence. J Clin Epidemiol. 2020;119:92-9. https://doi.org/10.1016/j.jclinepi.2019.12.003.

12. Munn Z, Moola S, Lisy K, Riitano D, Tufanaru C. Methodological guidance for systematic reviews of observational epidemiological studies reporting prevalence and cumulative incidence data. Int J Evid Based Healthc. 2015; 13(3):147-53. https://doi.org/10.1097/xeb.0000000000000054.

13. Salehi Z, Almasi-Hashiani A, Sahraian MA, Eskandarieh S. Epidemiology of familial multiple sclerosis: a population-based study in Tehran during 19992018. Mult Scler Relat Disord. 2020;43:102178. https://doi.org/10.1016/j.msa rd.2020.102178.

14. Dorche MS, Nikseresht A. The prevalence of familial multiple sclerosis in shiraz, southern Iran. Mult Scler Relat Disord. 2020;37:101530. https://doi. org/10.1016/j.msard.2019.11.005.

15. Ceccarelli A, Mifsud VA, Dogar A. Demographic and clinical characteristics of familial and sporadic multiple sclerosis: a single center exploratory study from Abu Dhabi. J Clin Neurosci. 2020;76:145-7. https://doi.org/10.1016/j. jocn.2020.04.007

16. AlJumah M, Otaibi HA, Al Towaijri G, Hassan A, Kareem A, Kalakatawi M, et al. Familial aggregation of multiple sclerosis: results from the national registry of the disease in Saudi Arabia. Mult Scler J Exp TransI Clin. 2020;6(4): 2055217320960499. https://doi.org/10.1177/2055217320960499.

17. Mohebi F, Eskandarieh S, Mansournia MA, Mohajer B, Sahraian MA. Multiple sclerosis in Tehran: rising prevalence alongside stabilizing incidence - true increase or enhanced diagnosis? Arch Iran Med. 2019;22(8):429-34.

18. Eskandarieh S, Sahraiain MA, Molazadeh N, Moghadasi AN. Pediatric multiple sclerosis and its familial recurrence: a population based study (1999-2017). Mult Scler Relat Disord. 2019;36:101377. https://doi.org/10.101 6/j.msard.2019.101377.

19. Abbasi V, Amani F, Aslanian $R$, Atalu A. The prevalence of familial multiple sclerosis (FMS) in Ardabil province, Ardabil, Iran. Narayana Med J. 2019;8(2): 59-63. https://doi.org/10.5455/nmj./00000168.

20. Yamamoto E, Ginsberg M, Rensel M, Moodley M. Pediatric-onset multiple sclerosis: a single center study. J Child Neurol. 2018;33(1):98-105. https://doi. org/10.1177/0883073817739789.

21. Viswanathan S, Rose N, Arip M, Chai CH, Law WC, Sim R, et al. Multiple sclerosis and neuromyelitis optica spectrum disorders in Malaysia: a comparison in different ethnic groups. Mult Scler Relat Disord. 2018;25:3008. https://doi.org/10.1016/j.msard.2018.07.003.

22. Omrani F, Sahraian MA, Saeen AA, Omrani Z, Hayeri G. Early-onset multiple sclerosis: reports of 300 patients from Iran. J Pediatr Neurosci. 2018;13(2): 137-40. https://doi.org/10.4103/jpn.JPN_122_17.

23. Eskandarieh S, Molazadeh N, Moghadasi AN, Azimi AR, Sahraian MA. The prevalence, incidence and familial recurrence of multiple sclerosis in Tehran, Iran. Mult Scler Relat Disord. 2018;25:143. https://doi.org/10.1016/j.msard.201 8.07.023.

24. Eskandarieh S, Allahabadi NS, Sadeghi M, Sahraian MA. Increasing prevalence of familial recurrence of multiple sclerosis in Iran: a population based study of Tehran registry 1999-2015. BMC Neurol. 2018;18(1):15. https://doi.org/10.1186/s12883-018-1019-2.

25. Eskandarieh S, Nedjat S, Abdollahpour I, Moghadasi AN, Azimi AR, Sahraian MA. Comparing epidemiology and baseline characteristic of multiple sclerosis and neuromyelitis optica: a case-control study. Mult Scler Relat Disord. 2017;12:39-43. https://doi.org/10.1016/j.msard.2017. 01.004

26. Eskandarieh S, Heydarpour P, Elhami SR, Sahraian MA. Prevalence and incidence of multiple sclerosis in Tehran, Iran. Iran J Public Health. 2017; 46(5):699-704

27. Schiess N, Huether K, Fatafta T, Fitzgerald KC, Calabresi PA, Blair I, et al. How global MS prevalence is changing: a retrospective chart review in the United Arab Emirates. Mult Scler Relat Disord. 2016;9:73-9. https://doi.org/1 0.1016/j.msard.2016.07.005.

28. Rojas Jl, Patrucco L, MI J, Sinay V, Cassara FP, Cáceres F, et al. Disease onset in familial and sporadic multiple sclerosis in Argentina. Mult Scler Relat Disord. 2016;6:54-6. https://doi.org/10.1016/j.msard.2016.01.004.

29. Mazdeh M, Khazaei M, Hashemi Firouzi N, Ghiasian M. Frequency of multiple sclerosis (ms) among relatives of ms patients in hamadan society, Iran. Avicenna J Neuro Psycho Physiol. 2016;3(1):0.

30. Etemadifar M, Nourian SM, Nourian N, Abtahi SH, Sayahi F, Saraf Z, et al. Early-onset multiple sclerosis in Isfahan, Iran: report of the demographic and clinical features of 221 patients. J Child Neurol. 2016;31(7):932-7. https://doi. org/10.1177/0883073816634853.

31. Alifirova VM, Titova MA, Terskikh EV, Musina NF, Sjomkina AA, Gumenyuk Y. Familial multiple sclerosis in Tomsk region. Zh Nevrol Psihiatr Im SS Korsakova. 2016;116(Special Issue 10):6-9. https://doi.org/10.17116/jnevro201 61161026-9.

32. Abedini M, Paksersht M, Rafiei A, Valadan R, Amjadi O, Khajavi R, et al. Demographic and clinical characteristics of multiple sclerosis. J Mazandaran Univ Med Sci. 2016;25(132):13-22.

33. Papais-Alvarenga RM, Pereira FFCC, Bernardes MS, Papais-Alvarenga M, Batista E, Paiva CA, et al. Familial forms of multiple sclerosis and neuromyelitis optica at an MS center in Rio de Janeiro state. Brazil J Neurol Sci. 2015;356(1-2):196-201. https://doi.org/10.1016/j.jns.2015.06.034.

34. Toghianifar N, Etemadifar M, Sharifzadeh A, Nasr Z. Characteristics of familial multiple sclerosis in Isfahan, Iran: a cross-sectional study. Neurol Asia. 2014; 19(1):59-62.

35. Reinhardt K, Weiss S, Rosenbauer J, Gärtner J, von Kries R. Multiple sclerosis in children and adolescents: incidence and clinical picture - new insights from the nationwide German surveillance (2009-2011). Eur J Neurol. 2014; 21(4):654-9. https://doi.org/10.1111/ene.12371.

36. Hader WJ, Yee IM. The prevalence of familial multiple sclerosis in Saskatoon, Saskatchewan. Mult Scler Int. 2014;2014:545080-7. https://doi.org/10.1155/2 014/545080.

37. Alroughani R, Ahmed SF, Al-Hashel J. Demographics and clinical characteristics of multiple sclerosis in Kuwait. Eur Neurol. 2014;72(3-4):1815. https://doi.org/10.1159/000362270.

38. Tipirneni A, Weinstock-Guttman B, Ramanathan M, Abdelrahman N, Hussein S, Hagemeier J, et al. MRI characteristics of familial and sporadic multiple sclerosis patients. Mult Scler. 2013;19(9):1145-52. https://doi.org/10.1177/13 52458512469697.

39. Saman-Nezhad B, Rezaee T, Bostani A, Najafi F, Aghaei A. Epidemiological characteristics of patients with Multiple Sclerosis in Kermanshah, Iran in 2012. J Mazandaran Univ Med Sci. 2013;23(104):97-101.

40. Rezaali S, Khalilnezhad A, Naser Moghadasi A, Chaibakhsh S, Sahraian MA. Epidemiology of multiple sclerosis in Qom: demographic study in Iran. Iran J Neurol. 2013;12(4):136-43.

41. Hashemilar M, Ouskui DS, Farhoudi M, Ayromlou, Asadollahi A. Multiple sclerosis in East Azerbaijan, North West Iran; 2011.

42. Banwell B, Bar-Or A, Arnold DL, Sadovnick D, Narayanan S, McGowan M, et al. Clinical, environmental, and genetic determinants of multiple sclerosis in children with acute demyelination: a prospective national cohort study. Lancet Neurol. 2011;10(5):436-45. https://doi.org/10.1016/s1474-4422(11 )70045-x.

43. Ashtari F, Shaygannejad V, Heidari F, Akbari M. Prevalence of familial multiple sclerosis in Isfahan, Iran. J Isfahan Med Sch. 2011;29(138):555-61.

44. Sahraian MA, Khorramnia S, Ebrahim MM, Moinfar Z, Lotfi J, Pakdaman H. Multiple sclerosis in Iran: a demographic study of 8,000 patients and changes over time. Eur Neurol. 2010;64(6):331-6. https://doi.org/10.1159/ 000321649.

45. Kułakowska A, Bartosik-Psujek H, Hozejowski R, Mitosek-Szewczyk K, Drozdowski W, Stelmasiak Z. Selected aspects of the epidemiology of multiple sclerosis in Poland - a multicentre pilot study. Neurol Neurochir Pol. 2010:44(5):443-52. https://doi.org/10.1016/S0028-3843(14)60134-1.

46. Yamout B, Barada W, Tohme RA, Mehio-Sibai A, Khalifeh R, El-Hajj T. Clinical characteristics of multiple sclerosis in Lebanon. J Neurol Sci. 2008;270(1-2): 88-93. https://doi.org/10.1016/j.jns.2008.02.009.

47. Taraghi Z, llali E, Abedini MA, Zarvani A, Khoshnama I, Mohammadpour RA, et al. Quality of life among multiple sclerosis patients. Iran J Nurs. 2007; 20(50):51-9.

48. Saadatnia M, Etemadifar M, Maghzi AH. Multiple sclerosis in Isfahan, Iran. Int Rev Neurobiol. 2007;79:357-75. https://doi.org/10.1016/s0074-7742(07)79016-5.

49. Fricska-Nagy Z, Bencsik K, Rajda C, Füvesi J, Honti V, Csépány T, et al. Epidemiology of familial multiple sclerosis in Hungary. Mult Scler. 2007;13(2): 260-1. https://doi.org/10.1177/1352458506070767.

50. Peterlin B, Ristić S, Sepcić J, Vracko BK, Rako A, Lovrecić L, et al. Region with persistent high frequency of multiple sclerosis in Croatia and Slovenia. J Neurol Sci. 2006;247(2):169-72. https://doi.org/10.1016/j.jns.2006.04.002.

51. Etemadifar M, Janghorbani M, Shaygannejad V, Ashtari F. Prevalence of multiple sclerosis in Isfahan, Iran. Neuroepidemiology. 2006;27(1):39-44. https://doi.org/10.1159/000094235. 
52. Deryck O, Ketelaer P, Dubois B. Clinical characteristics and long term prognosis in early onset multiple sclerosis. J Neurol. 2006;253(6):720-3 https://doi.org/10.1007/s00415-006-0095-1.

53. Ebers GC, Koopman WJ, Hader W, Sadovnick AD, Kremenchutzky M, Mandalfino P, et al. The natural history of multiple sclerosis: a geographically based study. 8. Familial multiple sclerosis. Brain. 2000;123(3):641-9. https:// doi.org/10.1093/brain/123.3.641.

54. Gonzalez O, Sotelo J. Is the frequency of multiple sclerosis increasing in Mexico? J Neurol Neurosurg Psychiatry. 1995;59(5):528-30. https://doi.org/1 0.1136/jnnp.59.5.528.

55. Hader WJ, Elliot M, Ebers GC. Epidemiology of multiple sclerosis in London and Middlesex County, Ontario, Canada. Neurology. 1988;38(4):617-21. https://doi.org/10.1212/wnl.38.4.617.

56. Wikstrom J, Kinnunen E, Porras J. The age-specific prevalence ratio of familial multiple sclerosis. Neuroepidemiology. 1984;3(2-3):74-81. https:// doi.org/10.1159/000110844.

57. Cárdenas-Roldán J, Rojas-Villarraga A, Anaya JM. How do autoimmune diseases cluster in families? A systematic review and meta-analysis. BMC Med. 2013;11(1). https://doi.org/10.1186/1741-7015-11-73.

58. Yan K, Balijepalli C, Desai K, Gullapalli L, Druyts E. Epidemiology of pediatric multiple sclerosis: a systematic literature review and meta-analysis. Mult Scler Relat Disord. 2020;44:102260. https://doi.org/10.1016/j.msard.2020.102260.

59. Bigi S, Banwell B. Pediatric multiple sclerosis. J Child Neurol. 2012;27(11): 1378-83. https://doi.org/10.1177/0883073812452784.

60. Sawcer S, Hellenthal G, Pirinen M, Spencer CC, Patsopoulos NA, Moutsianas $\mathrm{L}$, et al. Genetic risk and a primary role for cell-mediated immune mechanisms in multiple sclerosis. Nature. 2011;476(7359):214-9. https://doi. org/10.1038/nature10251.

61. Gianfrancesco MA, Stridh P, Shao X, Rhead B, Graves JS, Chitnis T, et al. Genetic risk factors for pediatric-onset multiple sclerosis. Mult Scler. 2018; 24(14):1825-34. https://doi.org/10.1177/1352458517733551.

62. Romero-Pinel L, Martínez-Yélamos S, Gubieras L, Matas E, Bau L, Kremenchutzky $\mathrm{M}$, et al. Anticipation of age at onset in familial multiple sclerosis. Eur J Neurol. 2010;17(4):572-5. https://doi.org/10.1111/j.14 68-1331.2009.02870.x.

63. Briggs FBS, Yu JC, Davis MF, Jiangyang J, Fu S, Parrotta E, et al. Multiple sclerosis risk factors contribute to onset heterogeneity. Mult Scler Relat Disord. 2019;28:11-6. https://doi.org/10.1016/j.msard.2018.12.007.

64. Ramagopalan SV, Byrnes JK, Dyment DA, Guimond C, Handunnetthi L Disanto G, et al. Parent-of-origin of HLA-DRB1*1501 and age of onset of multiple sclerosis. J Hum Genet. 2009;54(9):547-9. https://doi.org/10.1038/ jhg.2009.69.

65. Smestad C, Brynedal B, Jonasdottir G, Lorentzen AR, Masterman T, Akesson $E$, et al. The impact of HLA-A and -DRB1 on age at onset, disease course and severity in Scandinavian multiple sclerosis patients. Eur J Neurol. 2007; 14(8):835-40. https://doi.org/10.1111/j.1468-1331.2007.01825.x.

66. Kantarci OH, Barcellos LF, Atkinson EJ, Ramsay PP, Lincoln R, Achenbach SJ, et al. Men transmit MS more often to their children vs women: the Carter effect. Neurology. 2006;67(2):305-10. https://doi.org/10.1212/01.wnl.000022 5070.13682.11.

67. Mahmudi L, Moslemirad M, Dabestani B, Shohani M, Azami M. Clinical and demographic features in Iranian multiple sclerosis patients: a systematic review and meta-analysis. Future Neurol. 2019;14(2):FNL19. https://doi.org/1 0.2217/fnl-2018-0025

68. Yamout Bl, Assaad W, Tamim H, Mrabet S, Goueider R. Epidemiology and phenotypes of multiple sclerosis in the Middle East North Africa (MENA) region. Mult Scler J Exp Transl Clin. 2020;6(1):2055217319841881. https://doi. org/10.1177/2055217319841881.

69. Simpson S Jr, Wang W, Otahal P, Blizzard L, van der Mei IAF, Taylor BV. Latitude continues to be significantly associated with the prevalence of multiple sclerosis: an updated meta-analysis. J Neurol Neurosurg Psychiatry. 2019. https://doi.org/10.1136/jnnp-2018-320189.

\section{Publisher's Note}

Springer Nature remains neutral with regard to jurisdictional claims in published maps and institutional affiliations.

\section{Ready to submit your research? Choose BMC and benefit from:}

- fast, convenient online submission

- thorough peer review by experienced researchers in your field

- rapid publication on acceptance

- support for research data, including large and complex data types

- gold Open Access which fosters wider collaboration and increased citations

- maximum visibility for your research: over $100 \mathrm{M}$ website views per year

At BMC, research is always in progress.

Learn more biomedcentral.com/submissions 